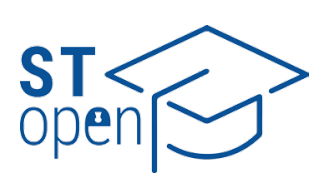

(C) 2021 The Author(s)

ST-OPEN @ 202

\title{
Social media marketing in Croatian consumerism
}

\section{Ivona Brtan (iD)}

Department of English Language and Literature, University of Split Faculty of Humanities and Social Sciences, Split, Croatia

\section{Correspondence to:}

Ivona Brtan

Faculty of Humanities and Social Sciences,

Poljička cesta 35,21000 Split, Croatia

brtan.ivona@gmail.com

Cite as:

Brtan I. Social media marketing in

Croatian consumerism. ST-OPEN. 2021; 2 .

e2021.2004.25.

DOl:

https://doi.org/10.48188/so.2.1
Aim: To investigate the impact of social media on consumer information processing and decision making processes related to purchasing via social media platforms. To examine how consumers differ in decision making and how they perceive credibility of social media and mass media marketing.

Methods: The study included a total of 161 adults (64 male and 97 female) whose participation was voluntary and anonymous. We used a questionnaire with 25 Likert scale questions in Croatian that addressed the decision making processes and the information processing theory. The questionnaire was accessible via Google Drive link. All submissions were complete.

Results: Facebook (41.0\%) and Instagram (42.9\%) were the most popular social media platforms among Croatian consumers in our sample. They spent several hours per week exposed to various contents available on these platforms. Consumers' response to that content was affected by numerous factors, from word of mouth in their social circle (34.2\%) and other online information (34.7\%) available to their personal level of motivation and interest in what was being offered. With respect to the general attitude towards social media marketing, consumers belonged to one of the two streams. One stream found it useful mostly for allowing communication between consumers and companies (28.6\%) and the direct accessibility to other users' experience (30.4\%), a major factor in their attitude formation. In the other stream, the consumers were often irritated by the vast number of ads which appear on social media that do not match their interests or needs (52.1\%). Overall, the time Croatian users in our sample spent on social media decreased with age.

Conclusion: Regardless of their gender, Croatian consumers consider social media very accessible, yet sometimes unprofessional, whereas mass media appears to be less demanding and often imprecise in targeting consumer interests and needs. 


\section{Introduction}

The relationship between consumers and marketing has never been as strong as today. Until recently, people mostly had access to short mass media broadcasts, whereas nowadays consumers are exposed to various types of advertisements, from photos and textual ads to promotional videos and pop-up ads. Back in the 1970s, people were exposed to approximately 500 ads per day, while recent studies showed that this number goes up to 5,000 ads daily (Johnson, 2006).

Given that social media has replaced all traditional means of communication, today it is almost impossible to imagine the Internet without social platforms where people exchange opinions, experiences, and other relevant data. Today, more than 2.77 billion users have created a profile on at least one social media platform and the number is estimated to reach 3 billion people by 2021 (Statista, 2019). However, the transition from mass media, which has been the primary source of advertising and general information exchange before the appearance of social media platforms, has caused major changes not only in advertising but in consumer behavior as well. Nowadays, consumers actively participate in advertising instead of being passive recipients.

The psycholinguistic approach to social media marketing based on information processing theory and the consumer decision making process is still an undiscovered field and it is difficult to anticipate how it may develop in the future. On one hand, research has so far pointed out the benefits of social media marketing and its approach to consumers, from establishing a trustworthy relationship to providing user-oriented content relevant for their interests, as well as its shortcomings. On the other hand, research also indicates the necessity for more studies about the role of psycholinguistic elements in the decision making process (Appendix 1). Previous research (Weinberg, 2009; Weber, 2009) mostly analyzed the advantages and shortcomings of social media marketing, and it was not until several years later that Lee (2013), Madni (2014) and Rupin (2015) started researching consumers' point of view, thus combining marketing and psycholinguistics as two intertwined sides of the advertising process in the 21st century.

The main objectives of this study were twofold. Firstly, to identify the changes that social media marketing has brought to consumer behavior, more specifically to their information processing and decision-making process. Secondly, we examined consumers' perspective of the relationship between social media and mass media.

\section{Social Media Marketing}

Social media marketing refers to "a process that empowers individuals to promote their websites, products, or services through online social channels and to communicate with and tap into a much larger community that may not have been available via traditional advertising channels” (Weinberg, 2009, p. 3). From word of mouth, exchange of information about a product among people independent of the producer (Silverman, 2011), to interactivity, social media marketing gives creative space to everyone present online and enables all users to leave feedback anytime and anywhere. 
According to Weber (2009), previous marketing strategies used in mass media can be defined as broadcasts where consumers are being talked at, instead of talked with. With the arrival of the 21st century, social media have captured consumers' attention and time, thus reducing both the popularity and efficiency of mass media advertising. Alternatively, interactivity, content and a variety of different communication tools proved to be enough for social media to take over the marketing scene.

\section{Consumer Decision Making Process}

Social media enable better insight into consumers' interests and needs. In an attempt to discover what consumers undergo from the moment they see a certain product, to possible purchase and beyond, the consumer decision making model (Dewey, 1910) has been developed. The model supports a purchase theory divided into 5 stages a customer goes through from the moment they acknowledge the need for a certain product or service until the purchase itself:

Problem (need) recognition: an individual develops a purchase idea and makes the first step towards a buying decision (word of mouth, personal desires, television ads, etc.);

Information search: the individual tends to collect as much information as possible from different sources (social circle, ads, mass media, etc.);

Evaluation of alternatives: the individual evaluates the various alternatives present on the market to choose the best option according to their needs, interests, and budget;

Purchase of product: the individual purchases the selected product or service;

Post-purchase behavior: the individual analyzes the product or service, e.g. whether it was useful or not or was the purchase worth the money invested.

\section{Information Processing Theory}

Given the fact that an average Internet user has over 500 social connections, it is obvious that the word is spread out much faster online than offline. However, only a part of that information actually finds its way to the consumers. Babin and Harris (2012) introduced the information processing theory, representing all ways in which the information is perceived, evaluated and post-evaluated in the decision making process. Their information processing model consists of 5 components:

Exposure: Due to consumers' different personalities and lifestyles, there is no universal set of influences which will trigger every individual to undertake different consumption decisions.

Attention: Kahneman (1973) distinguished two types of attention: voluntary (relevant for consumers' current goals) and involuntary (caught by one of the environmental aspects).

Comprehension: People draw upon their experience, memory, and expectations to attach meaning to a stimulus. However, their comprehension is not always correct.

Elaboration: Babin and Harris (2012) claim that consumers remember messages which contain strong arguments accompanied by convincing evidence depending on their motivation and ability. 
Memory: Sensory memory stores information temporarily (200 - 500 milliseconds, up to 12 units), short-term memory serves for briefly storing information while processing for more permanent storage (10 - 15 seconds up to 1 minute, $7 \pm 2$ units), and finally, long-term memory relies on consumers' general world knowledge, and recalls previously learned information.

\section{Methods}

We analyzed the ways in which consumers in Croatia handle data available on social media as well as factors that affect their final decision when buying a particular product. We assessed the consumer decision making process and information processing theory in a sample of 161 adult participants (64 male and 97 female) whose participation was voluntary and anonymous. The participants were divided into four age groups: 18-25 $(n=83)$, 26-34 ( $\mathrm{n}=57), 35-49(\mathrm{n}=14)$ and 50+ $(\mathrm{n}=7)$. We used a questionnaire (Appendix 2) with 25 Likert scale questions in Croatian, with responses on a five-point scale: never -1 , rarely -2 , sometimes -3 , often -4 , and always -5 , as well as strongly disagree -1 , disagree -2 , neutral -3 , agree -4 , and strongly agree -5 . The instrument was designed according to Lee's questionnaire (2013), except that we transformed the Likert scale into numerical categories to facilitate the statistical analysis for this study. The questionnaire was accessible online via a Google Drive link shared in groups on several social media platforms. All of the participants fully completed the questionnaire.

The Ethics Committee of the University of Split Faculty of Humanities and Social Sciences approved this study.

\section{Results}

\section{Decision Making Process}

In our sample of Croatian social media consumers, social media marketing had a stronger impact on females than males concerning the consumer decision making process. Specifically, women tended to be more influenced by social media marketing and engagement overall than the males (Table 1). Both male (64.1\%) and female (75.2\%) consumers agreed that visual ads trigger their purchase actions the most. Moreover, they either think of social media as useful (37.5\% of men and $40.2 \%$ of women) or annoying ( $43.7 \%$ of men and $34.0 \%$ of women). Approximately $50 \%$ of both genders agreed that excessive exposure to irrelevant ads is the greatest shortcoming of social media marketing. Around $30 \%$ of the total sample shared the opinion that feedback from other consumers and the communication channel between consumers and manufacturers are the strongest advantages of advertising on social media. But, the most significant differences are obvious when studying the factors impacting their attitude formation towards a certain product, more precisely opinions of their social circle $(P=0.046)$, online information $(P=0.003)$ and product reputation $(P=0.062)$. Another disagreement was displayed in consumer attitude towards social media as tools increasing brand awareness, where $20.3 \%$ of men see it as an advantage in comparison to only $9.3 \%$ of women $(P=0.046)$. 
Generally, women developed a purchase idea more frequently, more often relied on social media both for information searching and an evaluation of alternatives, and had a stronger habit to complete a purchase and leave a post-purchase feedback of the product or service. However, when comparing the two genders, we noticed that the number of participants who regularly included social media in the process was quite low.

Table 1. Descriptive statistics for decision making phases and information processing between male $(n=64)$ and female $(n=97)$ consumers after being exposed to social media marketing

\begin{tabular}{|c|c|c|c|c|}
\hline \multirow[t]{2}{*}{ Variable } & \multicolumn{4}{|c|}{ Participants (n, row \%) } \\
\hline & Total $(n=161)$ & Men $(n=64)$ & Women $(n=97)$ & $\mathrm{P}+$ \\
\hline \multicolumn{5}{|l|}{ Age (years) } \\
\hline $18-25$ & $83(51.5)$ & $28(43.8)$ & $55(56.7)$ & 0.108 \\
\hline $26-34$ & $57(35.4)$ & $31(48.4)$ & $26(26.8)$ & 0.005 \\
\hline $35-49$ & $14(8.7)$ & $5(7.8)$ & $9(9.3)$ & 0.747 \\
\hline 50 and older & $7(4.4)$ & $0(0.0)$. & $7(7.2)$ & $N A^{*}$ \\
\hline \multicolumn{5}{|c|}{ Which social media do you most commonly use? } \\
\hline Facebook & $66(41.0)$ & $27(42.2)$ & $39(40.2)$ & 0.803 \\
\hline Twitter & $0(0.0)$ & $0(0.0)$ & $0(0.0)$ & NA \\
\hline Linkedln & $0(0.0)$ & $0(0.0)$ & $0(0.0)$ & NA \\
\hline YouTube & $24(14.9)$ & $15(23.4)$ & $9(9.2)$ & 0.014 \\
\hline Instagram & $69(42.9)$ & $22(34.4)$ & $47(48.5)$ & 0.077 \\
\hline Other & $2(1.2)$ & $0(0.0)$ & $2(2.1)$ & NA \\
\hline \multicolumn{5}{|c|}{ How many hours per week do you on average spend on social media? } \\
\hline 0 & $0(0.0)$ & $0(0.0)$ & $0(0.0)$ & NA \\
\hline $1-3$ & $53(32.8)$ & $27(42.2)$ & $26(26.8)$ & 0.042 \\
\hline $4-6$ & $46(28.6)$ & $17(26.6)$ & $29(29.9)$ & 0.647 \\
\hline 7-9 & $31(19.3)$ & $8(12.5)$ & $23(23.7)$ & 0.077 \\
\hline More than 10 & $31(19.3)$ & $12(18.7)$ & $19(19.6)$ & 0.895 \\
\hline \multicolumn{5}{|c|}{ How many hours per week do you on average spend with mass media (e.g. TV, radio, newspapers)? } \\
\hline 0 & $22(13.6)$ & $11(17.2)$ & $11(11.3)$ & 0.290 \\
\hline $1-3$ & $74(46.0)$ & $26(40.6)$ & $48(49.5)$ & 0.270 \\
\hline 4-6 & $34(21.1)$ & $16(25.0)$ & $18(18.6)$ & 0.327 \\
\hline $7-9$ & $12(7.5)$ & $5(7.8)$ & $7(7.2)$ & 0.888 \\
\hline More than 10 & $19(11.8)$ & $6(9.4)$ & $13(13.4)$ & 0.438 \\
\hline \multicolumn{5}{|c|}{ What kind of advertising attracts your attention the most? } \\
\hline Photo & $114(70.8)$ & $41(64.1)$ & $73(75.2)$ & 0.405 \\
\hline Text ad & $5(3.1)$ & $2(3.1)$ & $3(3.1)$ & 0.991 \\
\hline Pop-up ad & $4(2.5)$ & $2(3.1)$ & $2(2.1)$ & 0.671 \\
\hline Promotional video & $36(22.4)$ & $17(26.6)$ & 19(19.6) & 0.299 \\
\hline Other & $2(1.2)$ & $2(3.1)$ & $0(0.0)$ & NA \\
\hline \multicolumn{5}{|c|}{ What is your general opinion about advertising on social media? } \\
\hline It is useful & $63(39.1)$ & $24(37.5)$ & $39(40.2)$ & 0.731 \\
\hline It is interesting & $29(18.0)$ & $10(15.6)$ & $19(19.6)$ & 0.522 \\
\hline It is educational & $3(1.9)$ & $1(1.6)$ & $2(2.1)$ & 0.929 \\
\hline It is annoying & $61(37.9)$ & $28(43.7)$ & $33(34.0)$ & 0.213 \\
\hline Other & $5(3.1)$ & $1(1.6)$ & $4(4.1)$ & 0.359 \\
\hline
\end{tabular}


Table 1. Continued

\begin{tabular}{|c|c|c|c|c|}
\hline \multirow[t]{2}{*}{ Variable } & \multicolumn{4}{|c|}{ Participants (n, row \%) } \\
\hline & Total $(n=161)$ & Men $(n=64)$ & Women $(n=97)$ & $\mathrm{P}^{\dagger}$ \\
\hline \multicolumn{5}{|c|}{ Which of the factors listed below affect your attitude towards a product? } \\
\hline Opinions and experiences of peers/friends/family & $55(34.2)$ & $16(25.0)$ & $39(40.2)$ & 0.046 \\
\hline Information from mass media & $3(1.9)$ & $0(0.0)$ & $3(3.1)$ & NA \\
\hline Online information & $56(34.7)$ & $31(48.4)$ & $25(25.8)$ & 0.003 \\
\hline Former experience with a product & $42(26.1)$ & $13(20.3)$ & $29(29.9)$ & 0.175 \\
\hline Product reputation & $5(3.1)$ & $4(6.3)$ & $1(1.0)$ & 0.062 \\
\hline \multicolumn{5}{|c|}{ What kind of mass media (e.g. TV, radio, newspapers) would you consider to be the most suitable for advertising? } \\
\hline TV & $124(77.0)$ & $49(76.6)$ & $75(77.3)$ & 0.911 \\
\hline Radio & $11(6.8)$ & $4(6.3)$ & $7(7.2)$ & 0.812 \\
\hline Newspapers & $8(5.0)$ & $7(10.9)$ & $1(1.0)$ & 0.005 \\
\hline Magazines & $6(3.7)$ & $1(1.6)$ & $5(5.2)$ & 0.239 \\
\hline Other & $12(7.5)$ & $3(4.6)$ & $9(9.3)$ & 0.277 \\
\hline \multicolumn{5}{|c|}{ What do you consider as the most important feature of social media marketing? } \\
\hline Increased awareness of a particular product & $22(13.7)$ & $13(20.3)$ & $9(9.3)$ & 0.046 \\
\hline Useful feedback from consumers & $49(30.4)$ & $20(31.3)$ & $29(29.8)$ & 0.855 \\
\hline $\begin{array}{l}\text { Communication channel between consumers and manu- } \\
\text { facturers }\end{array}$ & $46(28.6)$ & $18(28.1)$ & $28(28.9)$ & 0.919 \\
\hline Greater choice of products and services & $40(24.8)$ & $12(18.7)$ & $28(28.9)$ & 0.146 \\
\hline Other & $4(2.5)$ & $1(1.6)$ & $3(3.1)$ & 0.542 \\
\hline \multicolumn{5}{|c|}{ What do you think is the greatest shortcoming of social media marketing? } \\
\hline Too wide choice of products & $17(10.6)$ & $7(10.9)$ & $10(10.3)$ & 0.899 \\
\hline False information on a particular product & $46(28.6)$ & $19(29.7)$ & $27(27.8)$ & 0.799 \\
\hline $\begin{array}{l}\text { Excessive exposure to ads that do not match your inter- } \\
\text { ests }\end{array}$ & $84(52.1)$ & $33(51.6)$ & $51(52.6)$ & 0.899 \\
\hline Reduced activity of older people on social media & $10(6.2)$ & $2(3.1)$ & $8(8.3)$ & 0.188 \\
\hline Other & $4(2.5)$ & $3(4.7)$ & $1(1.0)$ & 0.147 \\
\hline
\end{tabular}

*Not applicable.

†T-test for independent samples, comparison between men and women.

\section{Internal and external factors impacting consumer behavior in the purchase process}

Several factors play a major role in the consumer decision making process. The main reasons why the majority of both male and female consumers decided not to purchase a product were the lack of time or monetary funds $(P=0.827)$ as well as the risk $(P=0.965)$ (Table 2). Both male and female consumers were relatively similar in terms of their use of Facebook, LinkedIn, Instagram and forums as sources of information, but the biggest discrepancy is displayed for Twitter $(P=0.014)$. It is also worth mentioning that men and women had significantly different opinions on whether mass media still attracts people's attention $(P=0.010)$, as men were more confident in the statement than women. This similar disagreement was seen when both men and women were asked to compare if it is easier to search for information on social media than mass media $(P=0.050)$.

When analyzing the results for the impact of social media on consumer decision making phases, both genders shared their views of the 3rd (evaluation of alternatives) and 4th (product purchase) phases. However, there were significant differences in the 1st (prob- 
Table 2. Internal and external factors that affected consumers' decision making exposed to social media marketing $(n=161)$

Question/variable
Mean $\pm S D$ of expressed level of agreement of the participants*

$\underset{(n=161)}{\text { Total }} \quad \underset{(n=64)}{\text { Wen }}(n=97) \quad P$

Do you agree with the statement that social media allow you to actively search information about the advertised product?

$3.43 \pm 1.09 \quad 3.20 \pm 1.09 \quad 3.59 \pm 1.05 \quad 0.02$

Do you have a certain attitude towards a product before buying it?

$3.61 \pm 0.80 \quad 3.73 \pm 0.76 \quad 3.54 \pm 0.83 \quad 0.125$

Do you look for information that agree with your original attitude towards a product?

How often does an ad created on social media in accordance with your interests trigger a purchase?

Do you agree with the statement that advertising via mass media (e.g. TV, radio, newspapers) still attracts consumers' attention?

Do you agree with the statement that it is easier to search information on social media than in mass media (e.g. TV, radio, newspapers)?

To what extent do you use Facebook as a source of information before purchasing the product?

To what extent do you use Twitter as a source of information before purchasing the product?

To what extent do you use Linkedln as a source of information before purchasing the product?

To what extent do you use Instagram as a source of information before purchasing the product?

To what extent do you use forums as a source of information before purchasing the product?

Do you agree with the statement that advertisements and reviews of other users on social media encourage you to purchase new products?

Do you agree that social media ads are more trustworthy than ads in mass media (e.g. TV, radio, newspapers)?

Do you rely on information available on social media in case of possible concerns about a particular product?

Do you change the initial preference features for the product you plan to purchase after searching for relevant information on social media?

Do you change your attitude towards a particular product after reading reviews from other users on social media?

How often do you express your own opinion and experience regarding a product on social media after using it?

To what extent do social media ads affect the problem or need recognition phase?

To what extent do social media ads affect the product information phase?

To what extent do social media ads affect the search for alternative products phase?

To what extent do social media ads affect the evaluation of available information phase?

To what extent do social media ads affect the post-purchase phase?

Do you agree with the statement that social media make your decision-making process more complex when purchasing a product?

To what extent the means (e.g. time, money, etc.) affect your decision-making process?

To what extent the amount of available information affects your decision-making process?

To what extent the personal reasons affects your decision-making process?

To what extent the uncertainty and indecision affect your decision-making process?

To what extent the risk affects your decision-making process?
$2.90 \pm 0.91 \quad 2.81 \pm 1.04 \quad 2.96 \pm 0.81 \quad 0.320$

$2.50 \pm 0.82 \quad 2.38 \pm 0.86 \quad 2.58 \pm 0.78 \quad 0.125$

$3.12 \pm 1.11 \quad 2.84 \pm 1.18 \quad 3.30 \pm 1.03 \quad 0.010$

$3.78 \pm 1.15 \quad 4.00 \pm 1.17 \quad 3.64 \pm 1.10 \quad 0.050$

$2.53 \pm 1.29 \quad 2.42 \pm 1.40 \quad 2.60 \pm 1.20 \quad 0.395$

$2.14 \pm 1.37 \quad 1.81 \pm 1.21 \quad 2.35 \pm 1.43 \quad 0.014$

$1.14 \pm 0.50 \quad 1.13 \pm 0.52 \quad 1.15 \pm 0.48 \quad 0.711$

$2.61 \pm 1.41 \quad 2.83 \pm 1.48 \quad 2.47 \pm 1.33 \quad 0.117$

$2.73 \pm 1.31 \quad 2.78 \pm 1.36 \quad 2.70 \pm 1.28 \quad 0.705$

$\begin{array}{llll}2.91 \pm 1.22 & 2.71 \pm 1.19 & 3.04 \pm 1.22 & 0.099\end{array}$

$2.40 \pm 1.24 \quad 2.38 \pm 1.27 \quad 2.41 \pm 1.22 \quad 0.852$

$2.94 \pm 0.97 \quad 2.83 \pm 1.02 \quad 3.02 \pm 0.91 \quad 0.213$

$2.83 \pm 0.75 \quad 2.73 \pm 0.83 \quad 2.90 \pm 0.68 \quad 0.176$

$3.04 \pm 0.81 \quad 2.98 \pm 0.84 \quad 3.07 \pm 0.79 \quad 0.502$

$\begin{array}{llll}1.94 \pm 0.92 & 1.88 \pm 0.91 & 1.98 \pm 0.92 & 0.480\end{array}$

$2.88 \pm 1.17 \quad 2.53 \pm 1.17 \quad 3.10 \pm 1.11 \quad 0.002$

$3.13 \pm 1.08 \quad 2.95 \pm 1.22 \quad 3.25 \pm 0.96 \quad 0.090$

$2.92 \pm 1.24 \quad 2.84 \pm 1.34 \quad 2.97 \pm 1.17 \quad 0.531$

$2.96 \pm 1.13 \quad 2.91 \pm 1.25 \quad 2.99 \pm 1.05 \quad 0.648$

$2.86 \pm 1.25 \quad 2.59 \pm 1.28 \quad 3.04 \pm 1.21 \quad 0.026$

$1.98 \pm 1.04 \quad 1.92 \pm 0.99 \quad 2.02 \pm 1.07 \quad 0.557$

$3.79 \pm 1.12 \quad 3.81 \pm 1.21 \quad 3.77 \pm 1.05 \quad 0.827$

$3.17 \pm 1.06 \quad 3.27 \pm 1.02 \quad 3.10 \pm 1.09 \quad 0.343$

$2.47 \pm 1.05 \quad 2.39 \pm 1.17 \quad 2.53 \pm 0.96 \quad 0.425$

$2.52 \pm 1.09 \quad 2.40 \pm 1.18 \quad 2.59 \pm 1.02 \quad 0.303$

$2.71 \pm 1.15 \quad 2.70 \pm 1.10 \quad 2.71 \pm 1.18 \quad 0.965$

*For the statistical analysis, the Likert scale was transformed into the following numerical categories: never -1 , rarely -2 , sometimes -3 , often -4 , and always -5 , as well as strongly disagree -1 , disagree -2 , neutral -3 , agree -4 , and strongly agree -5 .

†T-test for independent samples, comparison between men and women. 
lem or need recognition) phase ( $P=0.002)$, the 2 nd (information search) phase $(P=0.090)$, as well as the 5 th and final (post-purchase evaluation) phase $(P=0.026)$.

In terms of social media reliability in comparison to mass media, the participants agreed that the newer and "omnipresent" type of marketing is more trustworthy than the old mass methods and techniques $(P=0.852)$.

\section{Exposure to social and mass media across age groups}

When comparing the time spent on social and mass media, the results from Figure 1 indicate that TV, radio and other mass media channels have lost their popularity (in comparison with social media usage shown in Figure 2) among users of all generations. The amount of people who spend more than 10 hours weekly on mass media was generally low. The situation was not very different with consumers from the third and fourth age group, of which only a few stated that they used traditional channels over 10 hours per week.

On the whole, the generation gap among consumers was obvious in relation to their use of social and mass media. In general, the younger the consumers were, the more time they spent on social and less on mass media, and vice-versa.

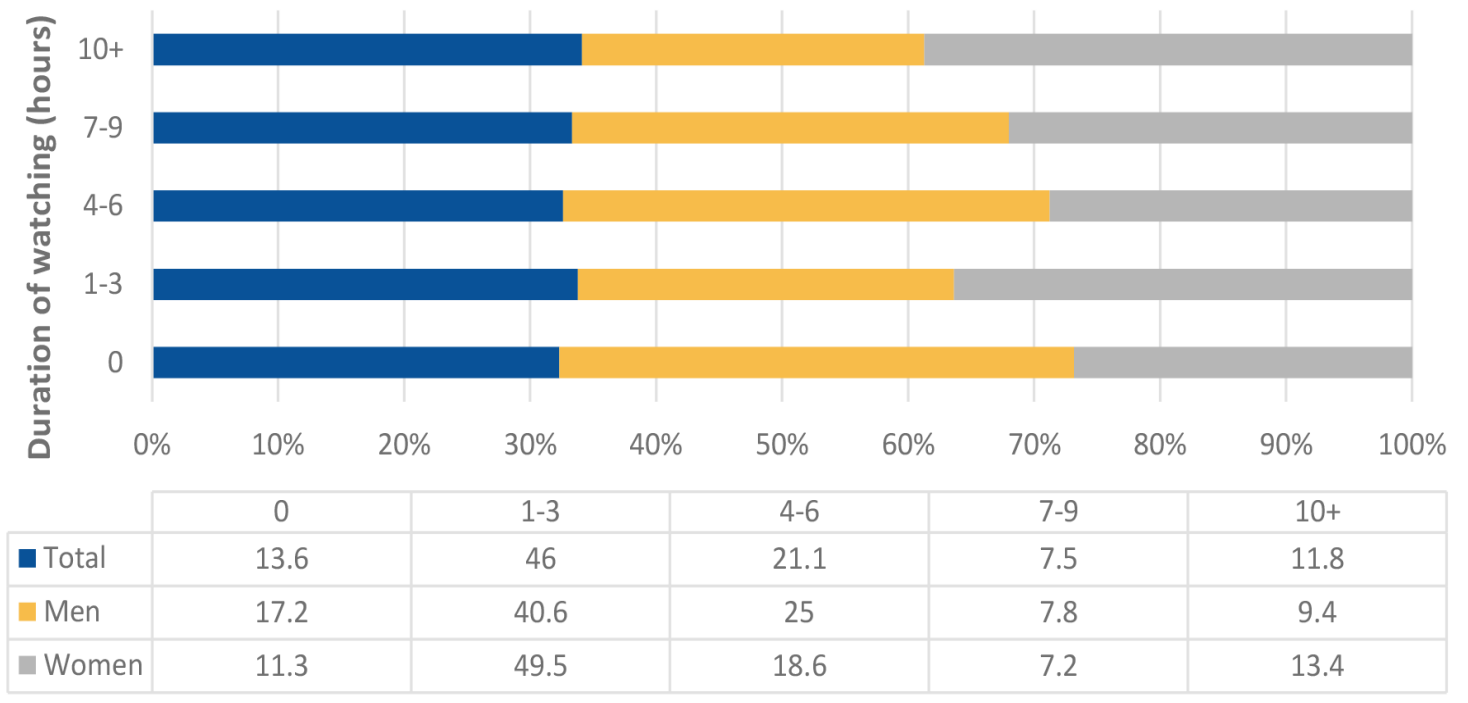

Percent of participants

- Total Men $\square$ Women

Figure 1. Weekly consumer exposure to mass media. Colors show the age of participants $(n=161)$.

\section{Factors affecting the consumer attitude}

In terms of factors affecting consumers' attitude towards the product, all age groups had different priorities. $43 \%$ of the youngest age group and $63 \%$ of the consumers over 50 were affected by the opinions and experiences of their social community, including peers, friends and family members. The information available online was the most important 


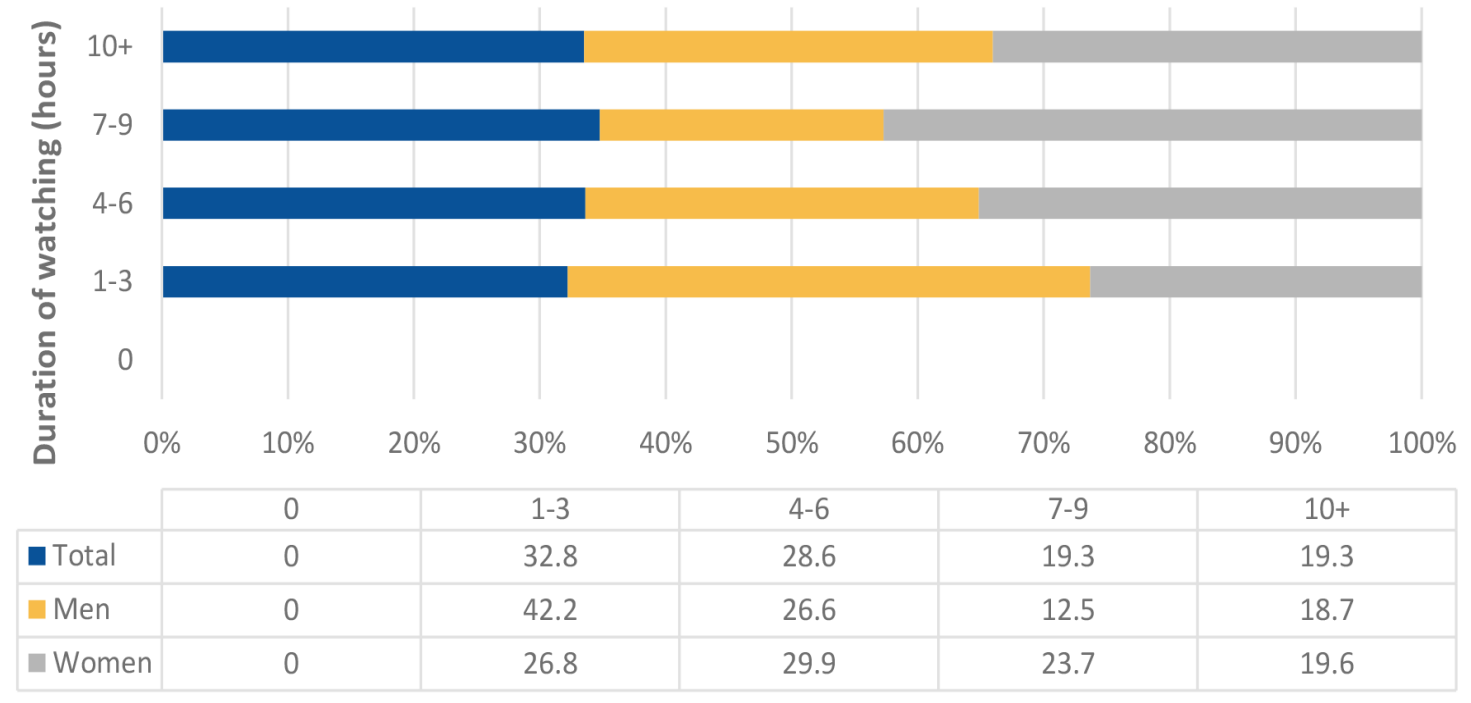

Percent of participants

- Total $\square$ Men $\square$ Women

Figure 2. Weekly consumer exposure to social media. Colors show the age of participants $(n=161)$.

factor in the purchase process for the second age group (46\%). Consumers' experience with a product was chosen as the primary condition by $61 \%$ of participants between 35 and 49 years old.

\section{Social media reliability}

When asked whether they considered social media marketing to be more credible in comparison to mass media marketing, over $39 \%$ of men and $24 \%$ of women from the youngest age group strongly disagreed that ads on social media are more reliable than those on mass media. Consumers belonging to the second age group shared the same opinion - $31 \%$ of men and almost $30 \%$ of women claimed to strongly disagree as well. However, almost $26 \%$ of women of the same age still believed that social media provide better ads compared to mass media.

Among consumers older than 35 and younger than 49 years of age, $60 \%$ of men, $50 \%$ of women and younger participants thought alike. However, almost $40 \%$ of the entire age group chose neither social nor mass media advertising. Additionally, only about $13 \%$ of consumers older than 50 years preferred social media marketing, unlike $25 \%$ of the group who either strongly disagreed with their peers or could not decide between the two options.

\section{Discussion}

The role of social media marketing in the decision making process of Croatian consumers in our sample was still not as sale-efficient as expected, as many participants claimed that they do not develop a purchase idea after being exposed to ads on social media. In general, 
these ads had a larger impact on women than on the male population. However, both men and women still did not consider social media as completely reliable sources of information and did not always tend to use it for researching the items they were interested in. In spite of its extreme popularity, neither male nor female consumers in our sample used social media platforms like Twitter, Facebook, and Instagram for more information on products. Moreover, our sample of Croatian consumers did not often rely on social media when searching for relevant information regarding the item they were interested in. Their main reason was ascribed to the multitude of false information about different products. Social media have not discovered a way or an algorithm to filter true information in the ocean of reviews, statutes, post and other data yet, which partly results in an increase in the number of people who are victims of fraud in false advertising (Daly, 2016).

Our study showed that women tended to believe more what they have been exposed to on social media and had a higher tendency for leaving feedback and sharing their experiences with others. Men, however, almost never did so and, among the offered social media, mostly relied on forums, but only as readers instead of active participants as well. Despite this, word of mouth has been recognized as a major advantage which helps the decision making process of consumers; we also found that our sample of Croatian consumers believed that social media allows facilitated communication with other customers and companies more effectively. However they were still not encouraged enough to express their attitudes to their social communities. Many consumers still thought that information available on social media platforms cannot provide answers to all their questions nor can provide the necessary feeling of trustworthiness, one of the most important elements in marketing of any kind.

With regard to consumer exposure to various social media platforms, consumers in our sample mostly used Facebook, Instagram, and YouTube. The time our sample of Croatian users spent on social media decreased with age. While being online in their social communities, consumers were exposed to a vast number of ads, of which they found photo ads and promo videos the most appealing. Thus, it can be stated that visual stimuli had the strongest impact on grasping the consumers' attention in our sample. However, it must be taken into consideration that nowadays visual ads on social media have become unavoidable, too recurring and often too long, causing above all frustration or loss of consumer interest. It is left to be seen what effect this very significant factor will have in the long run.

Despite the outburst of social media, Croatian consumers in our sample still actively used mass media channels by watching TV, reading magazines or listening to the radio. But, given the ever-growing popularity of social media and their involvement in people's daily routines, it is safe to assume that they do so less frequently than in the past. In general, younger women and older men spent more time on mass media than their peers of the opposite sex.

Detailed and comprehensive information on use and representation of mass media in Croatia is currently not available, therefore it is not possible to provide precise results on the changes in customer behavior in terms of mass media popularity. However, the generation gap and the speed at which technology adds new, better and improved (but also less self-dependent) features, imply that the traditional methods of advertising sim- 
ply cannot catch up to this. Thus, one can argue that mass media have been losing their popularity while being replaced by various social media platforms promoting products by numerous, and often very creative, methods. However, the use of traditional channels and mass media marketing is still very present and, according to the participants of the survey, television was by far the best platform for ads to be noticed by potential customers, whereas magazines or radios were preferred by only a small portion of the participants. Given that nowadays consumers are exposed to both types of marketing at the same time, they encounter a vast amount of information as well.

When choosing between those two kinds of marketing, it is obvious that Croatian consumers in our sample still did not consider social media and their form of advertising trustworthy and reliable enough to characterize them as more important roles in their decision making during a purchase process. Regardless of the advertising means they are exposed to, the main reasons why consumers in our Croatian sample decided to abandon the shopping process were lack of time or monetary funds as well as the risk of purchasing an unknown product or service. Although we cannot generalize our results on the Croatian population, they show that other customer reviews, numerous alternatives and a vast amount of information were still not enough to complete the action in our sample.

Our results indicate that, despite the general impression, social media marketing still did not gain consumers' trust in our sample, which is, apart from completing the purchase process, the ultimate long-term goal in every marketing process. But given the circumstances and extremely fast technological development accompanied by an even faster privacy loss, it is just a matter of time until the social platforms become the spamming tools.

Provenance: Submitted. This manuscript is based on the master's thesis by Ivona Brtan, deposited in the Dabar repository (https://urn.nsk.hr/urn:nbn:hr:172:305065).

Peer review: Externally peer reviewed.

Received: 19 January 2021 / Accepted: 9 February 2021 / Published online: 9 July 2021.

Ethics approval: The Ethics Committee of the University of Split Faculty of Humanities and Social Sciences approved this study.

Funding: This research received no specific grant from any funding agency in public, commercial or not-for-profit sectors.

Authorship declaration: IB is the sole author of the study.

Competing interests: The author completed the ICMJE Unified Competing Interest form (available upon request from the corresponding author), and declares no conflicts of interest.

Additional material: This article contains electronic supplementary material which is available for download at st-open.unist.hr.

\section{ORCID}

Ivona Brtan (D) https://orcid.org/0000-0001-5069-933X 


\section{References}

Babin, J. \& Harris E. (2012). Consumer Behaviour. Boston, Massachusetts, USA. Cengage Learning.

Daly, C. (2016, June 29). Misleading social media marketing faces serious consequences, CIM warns. Retrieved from: https://marketingtechnews.net/news/2016/jun/29/marketers-need-cleanmisleading-social-media-messages-or-risk-consequences-cim-says/.

Dewey, J. (1910). How We Think. Lexington, MA, USA. D. C. Heath \& Company.

Johnson, C. (2006, September 17). Cutting Through Advertising Clutter. Retrieved from: https://www. cbsnews.com/news/cutting-through-advertising-clutter/.

Kahneman, D. (1973). Attention and Effort. Englewood Cliffs, New Jersey, USA. Prentice Hall Inc.

Lee, E. (2013). Impacts of Social Media on Consumer Behaviour. Decision Making Process. Bachelor Thesis. Turku, Turku University of Applied Sciences, Finland. Retrieved from: https://www. theseus.fi/bitstream/handle/10024/62367/Lee_Ethel.pdf.

Madni, R. G. (2014). Consumer's Behaviour and Effectiveness of Social Media. Framingham, MA, USA. Global Journals Inc.

Statista. (2019, November 24). Number of social network users worldwide from 2017 to 2025. Retrieved from: https:/www.statista.com/statistics/278414/number-of-worldwide-socialnetwork-users/.

Rupin, C. (2015). Social Media as a New Engaging Channel in Brands' Relationship Marketing. Master Thesis. Helsinki, Helsinki Metropolia University of Applied Sciences, Finland. Retrieved from: https://core.ac.uk/download/pdf/38126391.pdf.

Silverman, G. (2011). The Secrets of Word of Mouth Marketing. New York, NY, USA. Amacom.

Weber, L. (2009). Marketing to the Social Web: How Digital Customer Communities Build Your Business. Hoboken, New Jersey, USA. John Wiley and Sons.

Weinberg, T. (2009). The New Community Rules: Marketing on the Social Web. Sebastopol, California, USA. O’Reilly Media Inc. 